\title{
Of false promises and good bets: a plea for a pragmatic approach to theory building (the Tartu lecture)
}

\author{
Friedrich Kratochwil \\ Department of Political and Social Sciences, European University Institute, Badia Fiesolana, Via \\ dei Roccettini, 9, San Domenico di Fiesole (Firenze) 50016, Italia. \\ E-mail: Friedrich.Kratochwil@eui.eu
}

In this lecture I review some of the issues that meta-theorizing was supposed to address in international relations and show how this project of securing knowledge through hierarchization and finding absolute foundations failed. Basically I argue that since neither the 'order of being' nor the categories of the mind provide an unproblematic and trans-historically valid Archimedean point that allows for an incontestable 'view from nowhere', the traditional epistemological project cannot make good on its promise. I'm trying to refute the twin fallacies that seem to fuel much of the hypertrophic concern with epistemology: First, that in the absence of secure universally valid and trans-historically established criteria everything becomes 'relative' and that, therefore, the adherents of a more critical or pragmatic orientation towards knowledge have to be either nihilists or charlatans since they deny 'truth'. Second, since the foundationalist claims of traditional epistemology can be shown to be faulty, indeed 'anything goes' and we need not worry about criteria that warrant our knowledge claims. Here relatively mindless research activism or some form of pragmatism at basement prices is supposed to take care of the problems. I argue for a pragmatic turn in theorizing not in the hope of having now found a new foundation after the failure of the epistemological project, but with the understanding that such a turn represents a good bet in pursuing our research while remaining attentive to the importance of meta-theoretical issues that arise in its course.

Journal of International Relations and Development (2007) 10, 1-15. doi:10.1057/palgrave.jird.1800111

Keywords: epistemology; meta-theory; pragmatic approach; research

\section{Introduction}

In this lecture I want to address the puzzle that emerges from a closer examination of theoretical debates within the field of international relations: why is it that a nearly hypertrophic concern with epistemological issues continues to characterize the field precisely when the foundationalist claims of 
epistemology have lost much of their lustre in philosophy, and when sociology has shown the deep embeddedness of scientific enterprise in social relations both in terms of the agenda or research programmes and in terms of how knowledge is produced (e.g. Knorr-Cetina 1999; Bourdieu 2000). Thus, should we not rather forget about the whole project of building upon Cartesian (or other) fundamenta inconcussa that, after all, turned out to be not incontrovertible? Should we not follow the path earlier scientists took when they rejected the metaphysical claims that in order to know anything about the world and its different forms of beings, one had to understand first 'being' itself? There are indeed always voices that try to prod us to 'get on' with actual research instead of debating ad infinitum some arcane epistemological issues such as the incommensurability of paradigms, the pros and cons of reductionism or materialist $v$ idealist explanations, just to name a few of the most familiar chestnuts.

While I certainly have much sympathy with the call for engaging with the actual problems of politics rather than with epistemological or entirely theoretically generated issues, such as, for example, that of 'cooperation' that is a puzzle only after one has bought into some of the more radical versions of realism - I shall argue, nevertheless, that the questions raised in epistemological debates are not that easily dispensed with. Without a clearer understanding of why and how we can circumvent fruitless meta-theoretical traps when going about our research, the old spectres are likely to haunt us sooner or later.

At this point, I seem to be in the uncomfortable position of arguing against the meta-theoretical strategy, which traditionally was charged with dissolving or dissipating the otherwise insoluble theoretical problems, while at the same time rejecting the idea that simply getting one's hands dirty in actual research provides us with a viable alternative. Consequently, I will have to spend most of this paper trying to dissolve this obvious paradox. I shall do this in the following fashion. First, I review some of the issues that meta-theorizing was supposed to address and show how this project of securing knowledge through hierarchization and finding absolute foundations failed. Basically I argue that since neither the 'order of being' nor the categories of the mind provide an unproblematic and trans-historically valid Archimedean point that allows for an incontestable 'view from nowhere', the traditional epistemological project cannot make good on its promise. Here, Kant's first Critique which perhaps best articulates the epistemological position and the more recent debates concerning the nature of logic and mathematics serve as my foil. They hopefully allow me to refute the twin fallacies that seem to fuel much of the hypertrophic concern with epistemology: First, that in the absence of secure universally valid and trans-historically established criteria everything becomes 'relative' and that, therefore, the adherents of a more critical or pragmatic 
orientation towards knowledge have to be either nihilists or charlatans since they deny 'truth'. Second, and in a way the flipside of the first fallacy, since the foundationalist claims of traditional epistemology can be shown to be faulty, indeed 'anything goes' and we need not worry about criteria that warrant our knowledge claims. Here relatively mindless research activism or some form of pragmatism at basement prices is supposed to take care of the problems.

The reason for these obvious quite absurd impasses seems to me to result from two uncritically accepted assumptions of traditional epistemology, that is, that truth is a property of the 'world' out there, and that there logically only exist two possibilities, as the traditional logical argument about the excluded middle implies. Either something is or is not. The first error leads us to believe that theorizing consists of attempts to grasp the 'world out there' by some conceptual matching operation. It thereby obscures the fact that our concepts are always deeply implicated in the construction of the 'world'. The second error results from the fact that traditional logic is indeed a poor philosopher stone for theorizing. Not only do experiments seldom result in clear 'yes' or 'no' answers but the class of 'undecidable' questions, which supposedly cannot exist, is embarrassingly large. ${ }^{1}$ Any scientist can attest to this, notwithstanding all attempts of establishing demarcation criteria or specifications of degenerative research programmes. ${ }^{2}$ A simple yes/no logic also fails to come to terms with the fact that something that is not white need not be black, and this means in practical terms that it provides us with not much guidance for finding out what is the case.

Recognizing the reasons for these two impasses brings some further implications. The first one, connected with the mirror theory of truth - that is, that theories are true if their conceptual apparatus matches the world 'out there' - is that if we recognize the constitutive nature of our concepts then we have to accept that we never 'test' against the 'real world' but only against other more or less well-articulated theories. In the same vein, we have to accept that 'truth' is not a property of the 'world out there' but of theoretically formed assertions about the world. Although 'truth' is thereby always relative to a frame of reference, it is not arbitrary, or contrary to reason, as some objections to such a 'relativism' imply.

Second, if the simple bi-valence principle of logic is neither able to adjudicate competing knowledge claims nor to provide for fruitful heuristics then attempts to see in logic, or even in the categories of reason itself, the guarantor of true knowledge, also have to fail simply because the epistemological project cannot deliver on its promise.

Third, which in a way follows from the second point: if traditional logic is not 'rich' enough to provide the supposedly incontrovertible foundations, then I am also not justified to believe that if this claim has been shown to be false the contrary has to be true and that therefore 'anything goes'. Instead, we have to 
search for and critically examine the criteria that lent some force to our assertions. Thus, quite contrary to the charges of some of the high priests or ayatollahs of mainstream political science that a critical stance towards the traditional conception of 'science' has ultimately to lead to 'nihilism', the espoused position obliges us to search for viable criteria for the assessment of our theories instead of relying on 'imports' from other fields and disciplines in the vain hope that these issues have been resolved somewhere else, be it in physics, logic, mathematics or philosophy.

It is for these reasons that after having visited the Kantian and then the NeoKantian debate which influenced logical positivism, I shall argue for a pragmatic turn in theorizing in the concluding section. I shall do so not in the hope of having now found a new foundation after the failure of the epistemological project, but with the understanding that such a turn represents a good bet in pursuing our research while remaining attentive to the importance of meta-theoretical issues that arise in its course.

\section{The Epistemological Project}

Knowing what a concept means is not only to know how it functions according to inter-subjective criteria of use, but also to understand its 'grammar'; that is, its relationship with other concepts and the logic of its development. Without wanting to claim an exhaustive or even extensive discussion of the term 'metatheory', I want to focus here on two formative moments, all connected with attempts at refuting the claims of scepticism. Here, Kant's transcendental turn is of particular importance as it removes the prop of a deus ex machina, that is, the notion that since a deceiving God is impossible (Descartes 1641/1984: particularly the Second and Third Meditation) it is still He who allows us to attain warranted knowledge. But Kant also answers the Humean sceptic by addressing the puzzle of induction that had preoccupied them and he also wrote at a time when Newtonian physics had disposed of natural entelechies, spiritual movers, the harmony of spheres, etc., while at the same time showing the superiority of a mechanical approach to understanding phenomena in the micro and macro cosmos.

In short, Kant $(1781,1787)^{3}$ seemed to provide the 'fundament' that Descartes had sought in vain and he mapped out a proper role for 'metaphysics' that has been deprived of its ontological moorings. Thus, for Kant secure knowledge can neither be provided by God nor by some primary 'clear and distinct ideas' that we encounter in experience. Instead, reason itself provides the justification as it reflects upon its own 'transcendental' conditions, that is, its presuppositions. As such, the latter are independent of all experience since they make any experience possible and thus lie before any perception and 
assertion about the world and its objects. Kant thereby attempted to answer the empiricists', dogmatists' and sceptics' challenges and to establish 'metaphysics' as a 'propaedeutic' science rather than as an ontological speculation above and beyond experience. The latter can only lead, according to him, to intrinsically endless, undecidable controversies (A, viii).

With this turn away from the object to the investigation of the preconditions of our knowledge as provided by reason itself, Kant hoped not only to set metaphysics onto 'the secure path of science' (B, vii) but he likened this turn to a 'Copernican revolution'. As he pointed out, the importance of the latter did not lie simply in the refutation of traditional astronomy but in the counterintuitive way in which truth is established by overcoming common sense and by unmasking the apparently uncontroversial 'empirical' evidence of the Sun going around the world as a mere appearance. His move instead entails an entirely new conception of 'objectivity' and of 'science' since, as Kant suggested, modern scientists such as Bacon, Gallileo and Toricelli were no longer vis-à-vis nature in the role of a "pupil who listens to everything a teacher chooses to say, but of an appointed judge, who compels the witnesses to answer questions which he himself has formulated' (B, xiii). Precisely because the procedure in this 'court' of reason is 'critical', Kant could reject both empiricism and dogmatism and provided an answer to sceptics who either deny the possibility of true knowledge or, like Hume, downgrade it by simply reducing it to some subjective psychological habit. As Otmar Höffe (1994: 34-35) points out:

In the tribunal to which Kant delegates the case 'dogmatism vs empiricism and scepticism, pure reason presides over its own case.... In the self critique reason manifests its power; however its power is self-limiting. In the first part of the Critique, the Aesthetic and Analytic, the legal code which contains a preliminary judgment of the controversy regarding metaphysics is found: in contrast to empiricist views, there are foundations free of experience and hence also strictly universal and necessary knowledge; this is however, in contradiction to rationalism, restricted to the sphere of possible experience. In the second part of the Critique, the Dialectic, the trial is carried out formally and arrives at a verdict. With reference to objects beyond all experience, reason proves to have no foothold. As soon as it becomes preoccupied solely with its own notions it runs into contradictions (Antinomies) [...]

In the course of its self-examination reason dismisses rationalism because reality cannot be known by mere thought. But reason also rejects empiricism. Kant admits that all knowledge begins with experience, but it does not follow, as empiricism presumes, that knowledge originates solely in experience. On the contrary, even empirical knowledge proves impossible 
without sources independent of experience. [e.g. the principle of causality supplied by reason] [...]

With the demonstration of conditions of experience themselves free of experience and hence universally valid, Kant shows that metaphysics is possible - but in contrast to rationalism only as a theory of experience, not as a science transcending the sphere of experience and in distinction to empiricism not as an empirical but rather as a transcendental theory of experience.

Here perhaps we find the most articulate version of the epistemological argument. Even if we do not want to follow Kant's further line of thought concerning the distinction between theoretical and practical reason, that is, the former which understands the world on the basis of causal necessities, the latter as a result of a free will determining itself, the epistemological foundation for knowledge seems widely accepted. Consequently, I want to examine a little more closely what this 'epistemological' position actually entails. This seems all the more important since relatively implausible claims are sometimes connected with it such as the 'unity of science' position which rests on NeoKantian foundations but which, as a whole, seems quite precariously perched on this or that Kantian argument. Similarly, while Kant's 'theory' of truth remains within the classical limits of reference, that is, the correspondence of concept and object, his transcendental turn implies that there can be no real 'test' of concepts and propositions directly against reality precisely because the subject is deeply implicated in the constitution of the object.

This recognition has three implications. First, since concepts do their work not through some 'mirroring' of the objects they are discursive rather than deictic or intuitive. Second, knowledge is also not simply limited to connecting phenomena causally. To show how things fit and are part and parcel of a larger order is as much an explanation as it shows a causal connection between two phenomena, a point that has surfaced in the recent debates about constitutive explanations (e.g. Wendt 1999: Chapter 2; Guzzini and Leander 2001). Third, since the objects of experience are not simply 'there' in the outer world but are the results of our constructions and interests, concept formation as well as theoretical assertions are never reducible to mere issues of inference, as Hume suggested. For one, the object such as, for example, a table is something entirely different for the physicist, the chemist, the cabinetmaker, the user, or the art historian. and it serves not much purpose to point out that there must be a common substratum (a point that is uncontested, but largely irrelevant). Second, concerning the issue of concept formation, the cognitive revolution has borne out Kant's arguments even if it has modified in important respects Kant's notion of an a-historical and transculturally valid concept of 'reason', which is characterized by universality and necessity. ${ }^{4}$ To that extent, the advice 
of some 'primers' of political science that the logic of 'inference' is the via regia to knowledge seems like a giant step in the wrong direction (King et al. 1994). It is bound to return us to the conundrum of empiricism and scepticism à la Hume - if the problems are taken seriously and not simply ignored, as is common nowadays - a dilemma from which Kant had just liberated us by circumventing it.

Thus, while Kant's first Critique certainly attempts to provide a foundational account of the nature of knowledge and its production, I think great care has to be taken not to over-burden his construction. True, Kant (1781: A, xx) himself perhaps invited such errors by his suggestions that 'not much was left for his successors', since his critique has 'put an end to all errors' (A, xii) and that 'most of the important problems have been resolved' (A, xiii). There is indeed some systematic reason to doubt that Kant could have espoused the position that epistemology was not only a critical reflection of reason upon its own presupposition, but that it also provided via the specification of the 'scientific method' the key for progress in the various sciences, as claimed by some Neo-Kantian interpretations that influenced the Vienna circle. After all, he never claimed that clarifying the presuppositions of knowledge through the a priori concepts of objects in general (1787: B, 25) increases our knowledge of the empirical world. Similarly, instead of pursuing the usual question of asking which propositions are true or false, Kant focused on the necessary preconditions of objective knowledge while, of course, seeing this objectivity as no longer rooted in ontology but as a function of the a priori conditions of the subject of knowledge.

Precisely because his transcendental critique is not concerned with the objects themselves, however constituted, it does not compete with the different sciences nor does it specify a field-independent proto-science that provides the paradigmatic understandings to the particular sciences, nor is it a critical reflection on the conceptual and theoretical developments within the sciences as the 'unity of science position' has attempted to deliver. Thus, while the Critique certainly contains a 'logic of truth' $(\mathrm{B}, 87)$, it neither tries to explicate its semantic dimension nor does it pragmatically specify the criterion or criteria by which we decide which system of propositions is true.

Seen from this perspective, nothing seems to be more foreign to the Kantian project than the specification of 'the' scientific method that could be 'applied' to the different fields of inquiry and that would provide us with universal and propositions as well as with cumulative knowledge of the world and its objects. On the other hand, we can also see that despite the existing gap between the knowledge of the objects of the world and the transcendental conditions of knowledge in general - a gap that no 'one size fits all' epistemology seems able to bridge - the inquiry into the nature of knowledge is no idle undertaking either, even though Kant himself admitted that the main function of his 
Critique may be 'only negative' since it does not 'extend' but only 'clarifies' our reason' $(\mathrm{B}, 25)$.

With these arguments in mind, we can quickly revisit the second modern site where epistemology was supposed to provide the key to solving puzzles that arose in both actual research and meta-theoretical disputes. Here the first issue concerned the apparent ambiguity in Kant himself in that his two critiques saw the construction of the world once as the result of a causal connection characterized by necessity and universality and once as a product of decisions of a free will determining itself and being able to set into motion new causal chains (Kant 1786). The emphasis on the free will as the basis of action was not only reinforcing the previous criticism of humanists like Vico (1744/1999) who had protested that the Cartesian search for the universal and necessary was fundamentally misunderstanding the social world that inevitably was contingent and had as a criterion not truth but the verisimile (the 'likely' instead of the 'true'). Here obviously probability theory and the theory of risk later provided some answers while treating genuine uncertainty essentially by the Bayesian method in which the updating of subjective probabilities is nevertheless based on a known probability distribution.

The more fundamental question concerned the controversy between 'erklaeren' and 'verstehen' that quickly emancipated itself from the naïve idea that we as actors have privileged access to their motives and that in order to understand an action we have to place ourselves 'in the shoes' of the agent in question, an operation that requires some form of empathy rather than reliance on 'external' causal accounts. Here Weber's contributions provided important impulses. He showed that although taking the 'subjective' point of view - a misleading term, since its semantics functions also as the opposite of objectivity and truth, a meaning that Weber definitely does not want to evoke - such a choice had little to do with empathy. We never can know what someone else actually thought and felt, but in trying to understand some action we always impute certain motives to actors. Like the later Wittgenstein, Weber suggested that taking the subjective point of view has little to do with psychologizing or examining the private ruminations of actors. While we certainly cannot feel someone else's pain, we nevertheless know most of the time what it is like and our communications about it are not simply meaningless because we have reached some personal or private realm that remains inaccessible (Wittgenstein 1964; Pitkin 1972: Chapter 6). Our explanations entail attributions to be tested and revised, but they are based on inter-subjectively shared understandings and culturally transmitted schemes that, as is also the case of language, cannot be reduced to idiosyncratic personal dispositions or utterances.

Further, since the facts for a social science are not natural but constituted by values, our interest in them is not simply limited to those incidents or social arrangements that are directly connected via causal chains to the 
present $^{6}$ - otherwise our interest in ancient Egypt or China would be unexplainable. Weber clearly has, despite his emphasis on 'causal relations' and in spite of his insistence on the fact/value distinction, a much broader understanding about the task of social science than some of his interpreters suggest, who link him via the Humean fork and 'causality' to a positivist conception of science. For one, his interest in ideal types and typologies (rather than generalizations) indicates that virtually all of Weber's explanations are of the constitutive rather the efficient causal type. In addition, his argument that 'value relations' (Wertbeziehungen) are constitutive of our social world and its 'facts' is more in tune with the tenets of constructivism than with the positivists' or even scientific realists' notion of the world 'out there'. Only Weber's insistence on the 'value freedom' of science and his treatment of politics as existing of essentially existential decisions (largely limited to leaders however) that are not susceptible to debates or persuasion (Weber 1977) link him, in a way, to the scepticism of Hume for whom value questions were, like matters of taste, beyond discussion (de gustibus non est disputandum).

There were, of course, several other sources that fed the epistemological debate at the beginning of the last century. The empiricist struggled with the problem of induction, and others who believed in the strict determinism of nature and the universal and time-reversible validity of natural laws were puzzled by the fact that the final mathematical solution to the three-body problem contradicted the classical implications of the Newtonian world view, as expressed by Laplace. As Poincaré's solution to the three body problem suggested - never fully embraced even by Poincaré himself even if it laid the foundation for chaos theory (Toulmin 2001: Chapter 4) - small changes in some of the parameters resulted in large changes later on so that the simple actio est reactio assumption could not be applied even to the development of natural systems of greater complexity. This meant not only that a gap opened up between determinism and predictability, but it also corrected the old notion that the universe would run again the same course when started all over again that is familiar from the mechanical imagery of clocks, springs and levers. With it, the belief that all of nature could be explained in terms of simple efficient causality ultimately had to be jettisoned as emergent properties, equifinality and multiple realizability made their appearance. Finally, it was modern quantum physics that showed the inappropriateness of the notion of a fixed already existing nature, whose 'discovery' was akin to lifting a veil as Einstein still believed. ${ }^{7}$

Even worse news for the foundationalist account came from the areas of mathematics and logic whose contradiction-free system of assertions had always been taken for granted. After all, it had served in the Cartesian and Kantian attempts as the main criterion for answering the quaestio juris in judging the truth or falsehood of assertions. As far as logic was concerned, the 
possibility of 'science' depended not only on the fact that 'nature' answered our questions in the experiments - even if with Kant we no longer can reach it directly but only in terms of our categorical framework and the synthetic a prioris - but that nature answers in terms of the clear yes or no scheme of logic that does not allow for a third category in between the 'is' or 'is not'. Thus, even the 'may be' is part of the 'is' category since frequency distributions have to be known. But, different from the latter, 'undecidable' questions challenge the bi-valence principle more frontally.

Classical logic, of course hinted at such a problem in the famous liar's paradox when, for example, 'Epimedes the Crete says: all Cretans are liars'. Here the truth conditions of the assertion are true and false at the same time. If the sentence is taken as true then it is false in what it asserts and vice versa. Paradoxes were, however, considered 'sophistry' and logic, like mathematics, was taken to be contradiction free and a stringent system of assertions. Nevertheless, the paradoxes raised the issue of the 'necessity' of logical sentences and thus required a justification of the very foundations of logic. But can logic provide a justification for its own foundations without this justification itself becoming self-referential and thus involving us in the very same problems of self-reference which give rise to the paradoxes in the first place? The attempts by Tarski and Carnap to solve the problem via the construction of a meta language distinct from the first-order object language seemed to point to a way out. But the solution not only presupposes the exact separation criteria between the languages on different levels, but also requires exact boundaries for each concept in the object language. (This is one reason why 'basic sentences' recording simple observations became a conditio sine qua non.)

Unfortunately, there are several difficulties that militate against reaching this goal. The first is that both Wittgensteinian language theory and the cognitive revolution in psychology (Lakoff 1987) have shown that our concepts do not function as simple matches of the objects 'out there', making their 'essence' transparent to us. What something is, is not simply recorded by a neutral observational language but is constituted by it. We most clearly see this in cases of institutions that are not natural but depend on conventions and rules governing human practices. But even in the 'natural' world, we usually begin with a paradigmatic case that best instantiates the concept and then extend its meaning through analogies. This inevitably makes for fuzzy boundaries and for 'undecidable' cases not only in the social sciences where 'contestable concepts' (like democracy, terrorism, humanitarian intervention, etc.) abound, but even in such presumably simple instances such as the classification of colours and spatial ordering, as Davis (2005) has shown.

Second, the implications of both Putnam's (1983) argument that even ideal languages can be false and Gödel's theorem that mathematics cannot be represented as a contradiction-free system suggest that such efforts will be 
unsuccessful. But if this is so, then the epistemological project providing us with the fundamenta inconcussa also has to fail. That such a bitter insight generates enormous anxieties and frequently results in charges of relativism or even nihilism against the bearers of this bad news is understandable, even if the self-righteous defence of 'truth' and 'science' is quite dogmatic and incompatible with the 'critical' intent with which the epistemological project was conceived. On the other hand, we have to realize that the world did not come to an end when we became aware that it was not at the centre of the solar system or even the universe, accepting the failure of the epistemological project does not amount to 'nihilism' or the denial of truth. It simply suggests that the way we have pursued it has ended in an impasse. Concepts are not a simple representation of a fixed world 'out there' and, consequently, assertions about this world cannot be justified in terms of a truth conditional theory of meaning as (logical) positivism or empiricism, for that matter, suggested. But recognizing that this way is unfeasible is not tantamount to showing that there is no other way, as the charge of 'nihilism' implies. Instead of taking the ontological route of Plato and the scholastics, or the subjective route of Kant which 'deduces' the categories from the working of reason itself, we have to trace back our steps and see at what crossings other paths offer themselves as an alternative. In this way, we could avoid the old impasses and be free to explore new avenues that are suggested by a new perspective.

\section{Pragmatism as a Good Bet}

Here pragmatism ${ }^{8}$ seems to hold some promise for several reasons. First, as its most basic level it does not begin with 'things' or with 'reason' or thought, but with 'acting' (prattein), thereby preventing some false starts. Even if the most rigorous and secure system of thought turns out not to be contradiction free, this revolutionary realization does not prevent mathematicians from going on to solve problems and most of us have to act most of the time without having the privilege of basing our decisions on secure universally valid knowledge. Thus, the cure of the anxiety induced by radical doubt consists not of the discovery of absolute certainty, which is a phantasmagorical undertaking that is engendered by its equally fantastic starting point, since nobody begins with universal doubt (e.g. Pierce 1868/1997)! Rather, the remedy for this anxiety consists of the recognition of the unproductive nature of universal doubt. Letting go of unrealizable plans and notions that lead us down the road to delusional projects and acquiring instead the ability to 'go on' in spite of uncertainties and the unknown is probably the most valuable lesson to learn.

Second, by giving up on the idea that warranted knowledge is generated through either logical demonstration or the representation of the world 'out 
there', a pragmatic starting point not only takes the always preliminary character of scientific knowledge seriously but it also accounts for cumulative knowledge in a more coherent fashion. If the world 'out there' were ready made only to be discovered, then scientific knowledge would have to be a simple accumulation of more and more true facts, leading us virtually automatically closer and closer to 'the Truth' conceived as the totality of all true statements. Here Popper's (1972) 'Third World' comes to mind and his first interpretation of scientific progress as the self-correcting process of conjectures and refutations. But as the history of science has suggested, scientific progress was characterized by conceptual revolutions and not only 'normal' science, quite aside from the embarrassing problem of what to do with all those parts of the 'third world' that turned out to be false after all, such as the indivisibility of atoms, ether, phlogiston, or what have you. Similarly misleading is the imagery of scientific progress as an ever closer approximation to 'the Truth' without, however, ever reaching it, thereby foxing the problem of revision. Obviously the image of approximation in Popper's (1963: Chapter 10) verisimilitude argument draws its persuasiveness from the successive approximation of polygons in approaching the perimeter of a circle, when determining the enclosed area. But if we have learned anything from the studies of various disciplines, then it is the fact that progress consists of being able to formulate new questions that could not even be asked previously. Thus, whatever we think of Kuhn's argument about 'paradigms', we have to recognize that in times of revolutionary change the bounds of sense are being revolutionized and we do not simply now know some more of the encircled area! ${ }^{9}$

Third, pragmatism recognizes that science as a process of knowledge production is a social practice determined by rules in which scientists are not only constitutive for the definitions of problems (rather than simply lifting a veil over nature), they also debate questions that seem 'undecidable" have to 'weigh' the evidence, instead of being able to rely on the bi-valence principle of logic as an automatic truth finder (Kratochwil 2007). To that extent, the critical element of the epistemological project is retained, only that the 'court' which Kant believed to be reason itself, consists of the practitioners themselves. Instead of applying the standards as suggested by the epistemological project and the unity of science position, each science provides its own court and judges the appropriateness of its own methods and practices.

But in staying with the Kantian metaphor of a 'court', we also have to correct Kant who apparently adhered to a quite implausible interpretation of law, that is, that it has to yield determinate and unique decisions. However, we know from jurisprudence and from case law that cases can be decided quite differently, without justifying the inference that this proves the arbitrariness of law. Determinacy need not coincide with uniqueness neither in logic (multiple equilibrium), science (equifinaliy) or law (notwithstanding Ronald Dworkin 1977)! 
Fourth, as the remarks above show, despite the fact that truth is no longer a function of bi-valent truth conditions and no longer anchored either in things themselves (as in classical ontology) or in reason itself (as in the foundationalist interpretation of the Kantian project), it has not been abolished or supplanted by an 'anything goes' attitude. Rather, it has become a procedural notion of rule-following in accordance with the practices of a community, as nobody can simply make the rules up as he goes along. These rules do not 'determine' outcomes, as the classical logic of deductions or truth conditions suggested, but they do constrain and enable us in our activities and allow us to go on.

Fifth, precisely because following rules does not simply result in producing multiple copies of a fixed template, assumed to be unchanging or universally valid like Plato's ideas, rules do provide us with orientation in new situations. In this way, we are able to accommodate both consistency and change when we engage in making validity claims. Validity now no longer has to assume a-historical universality as change is no longer conceived of temporal irreversibility, as when within differential equations time can be added and multiplied, compared to infinity and run towards the past or the future. 'History' is now able to enter the picture and it matters because, different from the old ontology, change can now be conceived as 'path-dependent' development, even as an evolution, or in the form of radical historicity and not only as contingency or decay impairing true knowledge.

Sixth, a pragmatic approach, although sensitive to the social conditions of cognition, is not simply another version of the old sociology of knowledge or of utilitarianism by accepting 'what works' or what seems reasonable to most people. It differs from the old sociology of knowledge that hinged on the cui bono question of knowledge (e.g. Mannheim 1936), as no argument about a link between social stratification and problem definition is implied here, not to mention the farther reaching Marxist claim of false consciousness. However, the pragmatist approach that I have espoused here is compatible with approaches such as Bourdieu's (1977), or more constructivist accounts of knowledge production such as Fuller's (1991) social epistemology, because it highlights the interdependence of semantics and social structures.

Our discussion should have in addition driven home the fact that it also should not be understood as some version of instrumentalism $\dot{a}$ la Friedman (1953/1968), accepting anything that provides for 'useful' predictions. Although the usefulness criterion is a pragmatic standard, not every employment of it satisfies the far more exacting criteria of a pragmatic approach. As I have suggested throughout, a coherent pragmatic approach emphasizes the inter-subjective and critical nature of knowledge generation based on rules that cannot be reduced to the de facto existing (or fabricated) consensus of a concrete group of scientists or to the utility of results whose presuppositions are obscure, because they remained unexamined. 
For all these reasons, it seems that taking a pragmatic attitude towards our research allows us to go on with our projects without the false hopes that a foundationalist notion of epistemology implies, and on which it cannot deliver, while remaining sensitive to the theoretical problems that arise in the course of our inquiries. Instead of relying on false promises, we will learn to follow a course of action that represents a good bet.

\section{Notes}

1 See, for example, the discussion by the physicist and philosopher of science John Ziman (1991).

2 See, for example, the discussion of the tortuous Popperian and Lakatosian attempts to provide such a demarcation criterion in Paul Diesing (1991: part 1).

3 Immanuel Kant's Critique of Pure Reason is quoted according to the two editions of 1781 (A) and of 1787 (B), as contained in the authoritative edition of the Preussische Akademie.

4 On the 'cognitive revolution' see, for example, Lakoff (1987).

5 For a good accessible account of the differences, see Hollis and Smith (1990).

6 See Weber's remarks in Roscher and Knies and especially his 'Zur Auseinandersetzung mit Eduard Meyer' (Weber 1985: 256).

7 For a mind-boggling account of the implications of the quantum revolution for our understanding of 'reality', see Zeilinger (2003).

$8 \mathrm{I}$ use here pragmatism in a wider sense as an approach to knowledge that takes its departure from acting rather than from reason itself, or from 'being' or speculation.

9 For a more extensive discussion of this point, see Kratochwil (2000).

10 On this point that many scientific experiments end in the aporetic situation that they are undecidable and that therefore they belong to a third class which the logical bivalence principle does not admit (tertium non datur), see the work of the physicist and philosopher of science John Ziman (1991).

\section{References}

Bourdieu, Pierre (1977) Outline of a Theory of Practice, Cambridge: Cambridge University Press. Bourdieu, Pierre (2000) Pascalian Meditations, Cambridge: Polity Press.

Davis, James (2005) Terms of Inquiry, Baltimore, MD: Johns Hopkins University Press.

Descartes, René (1641/1984) 'Meditations on First Philosophy', in John Cottingham, Robert Stoothaoff and Dugald Murdoch, eds, The Philosophical Writings of Descartes, Vol. 11, Cambridge: Cambridge University Press.

Diesing, Paul (1991) How Social Science Works, Pittsburgh, PA: University of Pittsburgh Press.

Dworkin, Ronald (1977) Taking Rights Seriously, Cambridge, MA: Harvard University Press.

Friedman, Milton (1953/1968) 'The Methodology of Positive Economics', in May Brodbeck, ed, Readings in the Philosophy of Social Sciences, 508-29, New York: Macmillan.

Fuller, Steven (1991) Social Epistemology, Bloomington, IN: Indiana University Press.

Guzzini, Stefano and Anna Leander (2001) 'A Social Theory for International Relations: An Appraisal of Alexander Wendt's Theoretical and Disciplinary Synthesis', Journal of International Relations and Development 4(4): 316-38.

Höffe, Ottfried (1994) Immanuel Kant, Albany, NY: State University of New York Press.

Hollis, Martin and Steve Smith (1990) Explaining and Understanding in International Relations, Oxford: Oxford University Press. 
Kant, Immanuel (1781) 'Kritik der reinen Vernunft (Akademie-Ausgabe A)', in Königlich Preussische Akademie der Wissenschaften (1922) Kants Gesammelte Schriften, Vol. 3, Berlin: de Gruyter.

Kant, Immanuel (1786) 'Kritik der praktischen Vernunft', in Immanuel Kant (1956) Werke, Vol. 2, Wiesbaden: Insel.

Kant, Immanuel (1787) 'Kritik der reinen Vernunft (Akademie-Ausgabe B)', in Königlich Preussische Akademie der Wissenschaften (1922) Kants Gesammelte Schriften, Vol. 4, Berlin: de Gruyter.

King, Gary, Robert Keohane and Sidney Verba (1994) Designing Social Inquiry: Scientific Inference in Qualitative Research, Princeton, NJ: Princeton University Press.

Knorr-Cetina, Karen (1999) How Sciences Make Knowledge, Cambridge, MA: Harvard University Press.

Kratochwil, Friedrich (2000) 'Constructing a New Orthodoxy? Wendt's "Social Theory of International Politics" and the Constructivist Challenge', Millennium: Journal of International Studies 29(1): 73-101.

Kratochwil, Friedrich V. (2007) 'Evidence, Inference, and Truth as Problems of Theory Building in the Social Sciences', in Richard Ned Lebow and Mark Lichbach, eds, Theory and Evidence in Comparative Politics and International Relations, New York: Palgrave, forthcoming.

Lakoff, George (1987) Women, Fire and Dangerous Things: What Categories Reveal about the Mind, Chicago, IL: University of Chicago Press.

Mannheim, Karl (1936) Ideology and Utopia, London: Routledge and Kegan Paul.

Pierce, Charles Sanders (1868/1997) 'Some Consequences of Four Incapacities', in Louis Menand, ed., Pragmatism: A Reader, 4-7, New York: Vintage.

Pitkin, Hannah (1972) Wittgenstein on Justice, Berkeley, CA: University of California Press.

Popper, Karl (1963) Conjectures and Refutations, New York: Harper.

Popper, Karl (1972) Objective Knowledge, Oxford: Clarendon Press.

Putnam, Hilary (1983) 'Models and Reality', in Hilary Putnam, ed., Philosophical Papers, Vol. 3, 1-25, Cambridge: Cambridge University Press.

Toulmin, Stephen (2001) Return to Reason, Cambridge, MA: Harvard University Press.

Vico, Giambattista (1744/1999) The New Science, translated by David Marsh, and an Introduction by Anthony Grafton, London and New York: Penguin.

Weber, Max (1977) Politik als Beruf, Berlin: Duncker und Humblodt.

Weber, Max (1985) 'Zur Auseinandersetzung mit Eduard Meyer', in Johannes Winckelmann, ed., Max Weber: Gesammelte Aufsaetze zur Wissenschaftslehre, Tübingen: J.C.B. Mohr.

Wendt, Alexander (1999) Social Theory of International Politics, Cambridge: Cambridge University Press.

Wittgenstein, Ludwig (1964) Preliminary Studies for the 'Philosophical Investigations', a.k.a. The Blue and Brown Books, New York: Harper and Row.

Zeilinger, Anton (2003) Einsteins Schleier: Die neue Welt der Quantenphysik, Munich: Beck.

Ziman, John (1991) Reliable Knowledge, Cambridge: Cambridge University Press.

\section{About the Author}

Friedrich Kratochwil holds the chair in International Politics at the European University Institute in Florence. He has published widely on international relations, social theory, international organization and international law in US and European journals. His latest book (edited with Ed Mansfield) is on International Organization and Global Governance (New York: Pearson, 2005). 